\title{
FERNANDO ROSENZWEIG
}

La inversión extranjera y el desarrollo de las manufacturas en México 1867 - 1940

1 urante el período que nos ocupa, la actividad manufacturera en abarcó hasta 1910, en que se detuvo por el estallido de la Revolución. La segunda discurrió de 1920 en adelante una vez que se consolidó el nuevo régimen, y fue sólo interrumpida de 1929 a 1933 por efectos de la crisis económica mundial.

Se trató en realidad de un desarrollo incipiente, apenas un comienzo, antecedente de la industrializacion en que entró México hacia 1940, y el cual no alcanzó a modificar significativamente la estructura de la economía: lo mismo que a fines de la década de 1890 , la participación del sector manufacturero en el monto del Producto Interno Bruto andaba por 16 por ciento hacia 1935, y el peso de este sector como fuente de empleo de la población se mantuvo en alrededor de 11 por ciento del total en ambas etapas (ver los cuadros 1 y2).

El cambio esencial a lo largo de esos años consistió en la aparición de las fábricas modernas, que vinieron a desplazar a amplios segmentos del artesanado tradicional del país, y que disfrutaron de la amplia protección del Estado para sustituir importaciones, especialmente de bienes de consumo.

El crecimiento de las actividades manufactureras en todos estos años reflejó la influencia predominante de factores internos que condicionaron la formación de capital en el sector y las tendencias de la demanda para sus productos.

La inversión extranjera reaccionó ante dichos factores, en razón de los cuales hizo sus primeras colocaciones en la industria de transformación, apenas una fracción de su monto total en el país (absorbido principalmente por la minería, los ferrocarriles y la 
generación de electricidad): poco menos de 4 por ciento en 1910 y alrededor de 7 por ciento en 1940.

En 1867 el país se liberó de la intervención francesa y quedaron consolidadas la independencia y las instituciones republicanas. Superada entonces la inestabilidad política que dominó el primer medio siglo de la vida independiente de Mexico, el conjunto del territorio nacional quedó sometido realmente a la jurisdicción del gobierno, en los términos de un sistema de normas jurídicas sancionadas formalmente por una representacion de la ciudadanía, la Constitución de 1857. Así garantizadas la paz pública y la seguridad y el tránsito de personas y mercancías, el territorio nacional (virtualmente aislado del resto del mundo por el arancel proteccionista) pudo comenzar a funcionar como un ámbito económico destinado a integrarse dentro de un único mercado. Las aduanas interiores fueron suprimidas en 1896. El establecimiento de una red ferrocarrilera, ${ }^{1}$ concebida principalmente para apoyar las exportaciones de bienes primarios, permitió articular entre sí las principales ciudades, las áreas productoras y los puertos marítimos y fronterizos.

La población total del país había aumentado en poco más de 30 por ciento en los 45 años transcurridos entre 1820 y 1865: de 6.2 a 8.2 millones de personas. En los siguientes 45 años el aumento fue en proporción bastante mayor, alrededor de 84 por ciento, para llegarse a un total de 15.1 millones de habitantes en 1910. La tasa anual, de 0.8 por ciento entre 1846 y 1878 , aumentó a 1.6 por ciento hasta 1910 . Las tendencias de la economía favorecieron el crecimiento de las ciudades, si bien en forma moderada. El número de ciudades mayores de 50 mil habitantes aumentó de 6 en 1900 a 7 en 1910 y en su total de pobladores ( $726 \mathrm{mil} \mathrm{y} 953$ mil respectivamente) aumentó de 5 por ciento a poco más de 6 por ciento del total del país. La proporción de alfabetizados subió modesta pero significativamente de 14 por ciento a 20 por ciento de las personas mayores de 10 años, entre 1895 y 1910.

1 Los kilómetros de vías férreas en servicio alrededor de mil en 1880 , aumentaron aproximadamente a 6 mil en 1884, 11 mil en 1894, 14 mil en 1900 y 19 mil en 1900. 
Además de la protección arancelaria, estimuló a las manufacturas la depreciación del peso, que levantaba una barrera adicional a las importaciones, lo que ocurrió casi ininterrumpidamente hasta 1905, en que México adoptó el patrón oro y con él una paridad fija para su moneda.

El desarrollo manufacturero se manifestó sobre todo en las industrias ligeras orientadas hacia el consumo de la población, destacando entre ellas la textil (del algodón y la lana); la del calzado; las de alimentos, bebidas y tabaco (entre ellas la azucarera y la cervecera); las lozas y porcelanas y la madera. También surgió la industria del cemento y dio sus primeros pasos - a partir de 1901 - la siderurgia.

Muchas de estas ramas industriales surgieron exclusivamente por la iniciativa y con lo recursos de capitalistas nacionales. $\mathrm{La}$ producción de azúcar, por ejemplo, se basó en las grandes haciendas cuyos campos cañeros pudieron abrirse en Morelos y otros estados, financiadas con ahorros de sus dueños y con créditos bancarios una producción en gran escala, gracias a las nuevas líneas ferroviarias.

En la industria textil el empresario mexicano había aparecido desde la década de 1830, titubeante, en un mercado débil, alentado por la política de franquicias del ministro Alamán. Después, en esta actividad y en otras, los capitales acumulados en manos de ricos comerciantes residentes en el país encontraron campo propicio de colocación en el establecimiento y modernizacion de fábricas. Algunos de esos comerciantes procedían de otros países (ingleses, franceses, españoles); sus capitales fueron hechos en México. En algunas ramas (ejemplo: la cervecera, la tabacalera y al final del período la siderúrgica) el capital extranjero llegó a sumarse al nacional, aportando patentes y técnicas, además de financiamiento. Pocas actividades podrían identificarse como privativas del inversionista foráneo.

La inversión extranjera en México existente en 1911 está estimada en 3401 millones de pesos (de la época), de los cuales apenas 131 millones - poco menos de $4 \%$ - correspondieron al sector manufacturero. La mayor porción ( 72 millones de pesos) era francesa, y estaba colocada en las ramas textiles, alcoholera y tabacalera. Los alemanes habían preferido las industrias cerveceras, la química y la del papel. Los norteamericanos participaban en las tenerías y los molinos de harina. 
En síntesis: entre 1867 y 1910, período de desarrollo económico impulsado por el auge del sector exportador, México registró los comienzos de un proceso de industrialización, que se apoyó en la integración del mercado interno y en una acumulación de capital de inversión dentro del país al que se sumaron algunas aportaciones de recursos del exterior. Para el sector exportador, el capital externo constituyó un factor clave; para las manufacturas, un apoyo complementario de la empresa nacional.

Explican las limitaciones del crecimiento de las manufacturas en México antes de 1920 dos grupos de factores, cuya acción contribuyó a determinar el cuadro de la crisis socio-económica surgida a finales del Porfiriato. Por una parte, la pobreza de las masas consumidoras del país, sobre todo las rurales, que formaban la gran mayoría, sujetas a un régimen de peonaje en las haciendas; ello detuvo tempranamente el crecimiento del mercado interno. Por otra parte, las cortas escalas de producción relacionadas con la debilidad del mercado, y la ineficiencia técnica de la industria (disimulada por el proteccionismo) debilitaron los incentivos para invertir en ella y le vedaron cualquier posibilidad de acceso a mercados del exterior.

Entre 1910, año en que estalló la Revolución, y 1921 en que se consolidó el nuevo régimen, la actividad manufacturera del país se mantuvo estancada, vegetando en medio de las condiciones adversas creadas por la interrupción de la paz pública y la inestabilidad de los gobiernos. Las principales industrias, sin embargo, pudieron mantener su actividad aprovechando la capacidad instalada existente, prácticamente sin realizar nuevas inversiones. Las del capital extranjero cesaron del todo.

Se carece de cifras sobre producción industrial correspondientes a los años de lucha armada (1911 a 1920). El dato correspondiente a 1921 indica un nivel inferior al de 1910 (ver el cuadro 1). La población sufrió un daño considerable; el total de habitantes censados bajó de 15.2 millones a 14.3 millones entre esos dos años. El capital físico del país quedó mermado, especialmente en los estados en que más se prolongaron las operaciones militares. En la mayor parte del territorio se desarticularon las comunicaciones y se perdió seguridad 
para transitar. Asombra que el impacto de los años de conflicto sobre las manufacturas no haya sido aún más grave.

\section{III}

Después de 1921 el país fue recuperando gradualmente la normalidad. La nueva Constitución Política proclamada en 1917, incorporó reformas sociales (consignando el derecho del trabajo y el reparto agrario), al lado de las garantías individuales establecidas en la anterior Constitución de 1857, y reivindicó el interés nacional en la explotación de los recursos naturales. Con la derrota militar de los partidarios del antiguo régimen, las nuevas instituciones quedaron formalmente asentadas, y con ello hubo de reinar de nuevo una paz. orgánica y estable.

El restablecimiento de las actividades productivas orientadas hacia el mercado interno señaló la tónica de la economía durante toda la década de 1920. Había que recuperar los niveles anteriores al período de la lucha armada, para poder abastecer a la población. Éste reanudó su crecimiento, llegando a cerca de 17 millones en 1930 y cerca de 20 millones en 1940 . Por otra parte, el poder adquisitivo de las masas trabajadoras recibió el impacto favorable de la expansión del gasto público (financiado en esa etapa por medio de mecanismos fiscales, predominantemente no inflacionarios), y de una distribución de ese gasto en que adquirieron mayor peso los objetivos de bienestar social y fomento económico. Así, la parte de los egresos totales que se destinó a administración general, 77\% al finalizar el Porfiriato, bajó a 65\% durante el gobierno de Calles (1925-28) y a $44 \%$ durante el de Cárdenas. Lo correspondiente a fomento económico subió de $16 \%$ a $25 \%$ y $38 \%$ respectivamente. $Y$ en cuanto a bienestar social, la proporción del gasto público aumentó de $7 \%$ a $10 \%$ y a $18 \%$ a lo largo de esos años. ${ }^{2}$

Se emprendió la construcción de obras de riego, en apoyo de la agricultura, y de un sistema nacional de carreteras. El crecimiento de la población urbana fue firme; de $20 \%$ al total de habitantes en 1910 pasó a poco menos de $36 \%$ en 1940. La ciudad de México alcanzó la marca del millón de habitantes en el censo de 1930.

El sector exportador había sido capaz de mantener su crecimiento durante los años de lucha armada, especialmente en las zonas de 2 Wilkie. 
agricultura tropical próximas a las costas (como la henequera de Yucatán) y en los pozos petroleros del Golfo de México, en respuesta a las demandas de productos estratégicos de la economía norteamericana durante la guerra de 1914-1918. En cambio, a lo largo de la década de 1920 el sector exportador se mostró menos dinámico, en parte por su resistencia a invertir conforme a las condiciones fijadas por la nueva legislación revolucionaria, y más tarde, durante los años de la crisis iniciada en 1929 , por el panorama adverso de la economía internacional.

El crecimiento de la actividad manufacturera ocurrido en el país desde 1921 respondió, pues, esencialmente, a una dinámica propia de la economía nacional en recuperación, alentado por una política de gasto público propicio a estimular la producción y fortalecer la demanda. Al igual que al finalizar el siglo XIX, el capital extranjero se vio atraído por las nuevas oportunidades que se abrían, y contribuyó a desarrollarlas. Entre las nuevas empresas con capital extranjero destacan a partir de entonces las norteamericanas. En 1926 se establece la primera armadora de automóviles (Ford) y en 1933 se inicia la fabricación de llantas, ambas ramas apoyadas en la construcción de carreteras. En 1936 se inicia el montaje de camiones (General Motors). Otros desarrollos con capital norteamericano abarcaron las pilas eléctricas, los equipos electro-domésticos, y siguió la entrada de este capital a la industria alimenticia. El gobierno de los Estados Unidos calculó que hacia 1940 las inversiones directas de sus nacionales en México ascendían en total a Dls. 358 millones y sólo en manufacturas, apenas Dls. 10 millones, menos de $3 \%$ del total. México conservaba su carácter de país exportador primario, pero su desarrollo interno comenzaba a abrir espacio para la inversión industrial.

Como puede verse en el cuadro 1 , los años de crisis mundial afectaron al crecimiento de las manufacturas en México, como consecuencia de la contracción general de la actividad económica resultante de la caída de las exportaciones. El malestar urbano ocasionado por el desempleo en la industria y los servicios, y los conflictos surgidos en el campo al sufrir una caída los cultivos comerciales, contribuyeron a preparar el ambiente del país para el programa de reformas estructurales realizadas por la administración del Presidente Cárdenas (1934-1940), cuya vertebración la dieron el reparto agrario y la puesta en vigor de las leyes del trabajo. Tales 
reformas, junto con el programa de obras públicas y la política de fomento económico del gobierno (orientada según enfoques anticíclicos de inspiración keynesiana), imprimieron un firme impulso de crecimiento a las actividades productivas; éstas pronto se recuperaron del impacto adverso de la crisis mundial y no tardarían en conquistar niveles más altos.

La expansión de la industria fue vigorosa a partir de 1935. Progresivamente, utilizándose la capacidad ociosa, y el sector comenzó a atraer nuevas inversiones, pronto también al capital extranjero. $\mathrm{Ni}$ aun la expropiación del petróleo a las empresas norteamericanas e inglesas, en 1938, detuvo la entrada de recursos del exterior con destino a las manufacturas. Sobre todo el capital norteamericano, encontró en éstas un nuevo campo de colocación, llamado a ser el preferente en los años que siguieron.

Cuadro 1. Producto Interno Bruto en México:

total y sector manufacturero

(millones de pesos de 1950)

Sector manufacturero

\begin{tabular}{lccc}
\hline ANOS & TOTAL & MONTO & \% DEL TOTAL \\
\hline 1895 & 6,493 & 890 & 13.5 \\
1900 & 8,250 & 1,360 & 16.5 \\
1910 & 11,650 & 1,836 & 15.8 \\
1921 & 11,273 & 1,669 & 14.8 \\
1926 & 16,622 & 2,330 & 14.0 \\
1931 & 16,016 & 2,296 & 14.3 \\
1932 & 13,547 & 1,682 & 12.4 \\
1934 & 17,983 & 2,820 & 15.7 \\
1940 & 22,889 & 4,264 & 18.6 \\
\hline
\end{tabular}

Fuente: L. Solís, La realidad económica mexicana: retrovisión y perspectivas, Siglo XXI, México, 1970, p.p. 90-92. 
Cuadro 2. Población activa en México:

total y sector manufacturero

(miles de personas)

Sector manufacturero

\begin{tabular}{llcc}
\hline ANOS & TOTAL & CANTIDAD & \% AL TOTAL \\
\hline 1895 & $4,761.9$ & 554.6 & 11.6 \\
1910 & $5,337.9$ & 613.9 & 11.5 \\
1921 & $5,883.6$ & 534.4 & 10.9 \\
1930 & $5,165.8$ & 692.2 & 13.4 \\
1940 & $5,858.1$ & 639.6 & 10.9 \\
\hline
\end{tabular}

Fuente: Censos nacionales de población. Nex: Instituto Nacional de Estadística, Geografía e Informática (INEGI), Estadísticas históricas de México, México 1985, tomo I, cp. 6.

\section{Obras consultadas}

Daniel Cosío Villegas, Historia moderna de México, El Porfiriato, La vida económica, Tomo I, Editorial Hermes, México, 1965.

Sanford A. Mosk, Industrial revolution in México, University of California Press, 1950.

Clark W. Reynolds, The mexican economy, twentieth century structure and growth, Yale University Press, 1970.

Bernardo Sepúlveda y Antonio Chumacero, La inversión extranjera en México, Fondo de Cultura Económica, México, 1973.

Leopoldo Solís, La realidad económica mexicana, retrovisión y perspectivas, Siglp XXI, México, 1970.

James W. Wilkie, The mexican revolution, expenditure and change since 1910, University of California Press, 1970.

G. Wythe, La industria latinoamericana, Fondo de Cultura Económica, México, 1947. 